\title{
El apoyo psicológico en catástrofes, crisis y emergencias
}

El interés por las consecuencias psicológicas de los afectados por catástrofes o situaciones nacionales de crisis ha ocupado siempre un lugar destacado. Sin embargo, no es hasta finales del siglo XX y comienzos del XXI cuando dicho interés se ha transformado en una estrategia de afrontamiento para algunas naciones. En este contexto, las intervenciones de los psicólogos han tenido un largo recorrido hasta convertirse en lo que ahora son. Hace algo más de tres siglos, la atención que se daba a los aspectos psicológicos en los desastres era meramente descriptiva, valga como ejemplo el relato de Samuel Pepys del fenómeno manifestado por algunos supervivientes al incendio de Londres de 1666, conocido actualmente como "flashbacks". Desde finales del siglo XIX y hasta algo más de la mitad del XX, siguió la tendencia descriptiva, con las primeras observaciones en catástrofes realizadas propiamente por psicólogos. Durante la II Guerra Mundial la actividad descriptiva llegó a crear nueva terminología y a fundar algunos principios básicos. Al finalizar esta Guerra, se produjo un cambio decisivo en el enfoque de estos sucesos gracias al auge de la orientación empírica a través del Grupo de Investigación en Desastres en los Estados Unidos y, en Europa, al Grupo de Doctores Noruegos.

Los equipos de apoyo psicológico en crisis iniciaron su actividad en la década de los 70 del siglo XX, debido a que varios autores detectaron y transmitieron la necesidad de llevar profesionales de salud mental rápidamente allí donde había ocurrido un desastre y así minimizar los daños psicológicos. Esta práctica se fue generalizando y haciendo cada vez más habitual. En España, tras la transición, comenzaron a promulgarse normativas para las situaciones de catástrofe, desgracia pública y crisis. Publicaciones que continuaron a la alza en los 90 y al empezar el nuevo siglo. Aunque la necesidad de dar atención psicológica fuera un objetivo desde la Ley 2/1985 y el Real Decreto 407/1992 fue, a partir de 1997, cuando estas acciones cobraron un lugar propio y destacado. Se creó el Grupo Interinstitucional de trabajo coordinado por el Equipo de Psicología en Catástrofes de la Dirección General de Protección Civil y formado por las distintas instituciones implicadas (Policía Nacional, Guardia Civil, Cruz Roja, Defensa, Servicios de Emergencia, Universidades y Colegio Oficial de Psicólogos). Entre las finalidades del mencionado grupo estaba la de definir un modelo y un plan de intervención psicosocial en catástrofes común a todo el territorio español. Además, se pudo perfilar cómo debían ser las intervenciones psicológicas en crisis, las características que debían tener los psicólogos, o qué contenidos debían tener los programas de formación de los distintos profesionales intervinientes. En la actualidad, estos equipos de psicólogos cuentan con un largo recorrido en sus intervenciones, como las realizadas cada vez que ha habido en España incendios, explosiones, catástrofes naturales, atentados terroristas o accidentes masivos.

El apoyo psicológico en el contexto militar español no ha estado, tampoco, exento del transcurso de la historia en general y de la historia de la psicología militar española en particular, siendo una función esporádica de los psicólogos militares desde los años 90 y demandada, explícitamente, a partir del Real De- creto 2394/2004. Por su parte, las Órdenes Ministeriales 66/2009 y 71/2010, no sólo supusieron un refuerzo para las familias y heridos, sino para todos los agentes implicados en el apoyo y acompañamiento, volviéndose a reconocer el papel del psicólogo en la normativa. Además, los psicólogos militares pueden ser demandados para dar apoyo psicosocial a personal civil en casos de emergencias graves o de interés nacional, según los convenios marco entre la Unidad Militar de Emergencias y el Sistema Nacional de Protección Civil.

Gracias a distintas revisiones sistemáticas de estudios empíricos, se sabe que los trastornos mentales son más elevados tras pérdidas violentas y repentinas que tras pérdidas por muerte natural. Además, la trayectoria de la recuperación es más lenta en el primer caso. Dentro de las muertes inesperadas, hay también diferencias a la hora de elaborar el duelo. La pérdida fortuita es más difícil de asimilar cuando es obra de la negligencia humana que cuando ésta es causada por una catástrofe natural o un accidente. Más difícil aún de digerir es cuando otro ser humano, voluntariamente, por diversión o por defender argumentos ilegítimos o totalitarios, emplea como diana a personas inocentes, estigmatizadas por un rasgo o que no comparten su ideología. Este asunto es relevante en el apoyo psicológico porque una de las principales preguntas que la víctima busca resolver, es la causa de su pérdida, las responsabilidades y culpas. Proceso que se manifiesta en forma de diálogo interno, normalmente intrincado, duradero y con un impactante componente emocional. Además, entre las reacciones psicológicas que suelen presentar los afectados por situaciones críticas y de emergencia se encuentran: los pensamientos invasores y recurrentes, la confusión, la culpa, las dificultades en la toma de decisiones, la negación o el bloqueo mental. A nivel emocional, la tristeza suele dominar a la persona, seguido de un profundo sentimiento de desesperanza, de ira y/o de miedo. Estas respuestas, totalmente normales ante hechos anormales, requieren de los psicólogos intervinientes que estén preparados no sólo a nivel técnico sino, también, afectivo y personal.

De este modo, las demandas a los psicólogos en situaciones de emergencia son variadas, pudiéndose dividir en tres fases diferentes. En las primeras, dichas demandas suelen ser: Contactar y conectar; ofrecer protección y seguridad; proporcionar información veraz; facilitar la comprensión; asesorar a los allegados de los afectados; mediar en conflictos; identificar y reducir los pensamientos distorsionados que puedan surgir; explicar la normalidad que hay en las reacciones emocionales, cognitivas, fisiológicas y conductuales que pudieran manifestar los implicados; dar claves para reducir la ansiedad; vigilar que el afectado duerme, come y bebe; indagar si hay psicopatología previa; fomentar y reforzar las estrategias de afrontamiento, el sentimiento de control y de autoeficacia; valorar factores de vulnerabilidad y protección; identificar posibles derivaciones profesionales; buscar apoyo social y/o especializado; preparar a la persona para reconocer cadáveres y acompañarla en el momento si así lo solicita; acompañarla en el entierro si así lo solicita. En fases posteriores, algunas de las demandas consisten en: realizar seguimien- 


\section{EDITORIAL}

tos, observar el proceso de asimilación de la pérdida, ayudar a elaborar el duelo, comprobar si ha habido pérdida de funcionalidad con respecto a la vida que llevaba antes del suceso, valorar las estrategias de afrontamiento, la autoestima o el sentimiento de autoeficacia, ayudar a la toma de decisiones, identificar los aspectos bio-psico-sociales que puedan estar interfiriendo en la adaptación a la nueva situación, o derivar a profesionales especializados si fuera necesario. A muy largo plazo, hay que comprobar que la persona ha conseguido rehacer su vida y adaptarse al cambio que supuso aquel suceso. Lo cual no significa olvidarlo, sino no seguir atrapado por él.

Aunque los miembros que forman los equipos de rescate y de apoyo puedan experimentar sentimientos de satisfacción laboral y de enriquecimiento personal por haber ayudado a otras personas en situaciones dramáticas, también se han descrito reacciones negativas en dichos profesionales tras intervenir en estas circunstancias. En los años 60 del siglo pasado, varios autores destacaron el impacto y deterioro psicológico a largo plazo por el que pasaron los miembros del equipo de primera respuesta al bombardeo atómico de Hiroshima y, en los 80, los miembros de los equipos de rescate llegaron a ser conocidos como "las víctimas ocultas de los desastres". Tanto los equipos de rescate, como los de apoyo, se enfrentan a un riesgo laboral debido a la elevada exigencia emocional que demandan estas intervenciones, pudiendo manifestar, tras ellas, "síndrome de fatiga por compasión", también conocido como "desgaste por empatía" o "estrés traumático secundario".

Las medidas para hacer frente a esta exigencia emocional del trabajo son variadas y todas dependen de la cadena mando. En un nivel primario, se debe formar al personal, tener protocolos de intervención, crear normativas que agilicen las distintas labores y hacer simulacros de entrenamiento. En un segundo nivel, se deben tener en cuenta las vicisitudes por las que están pasando los intervinientes en su vida privada antes de enviarlos a intervenir (problemas familiares, enfermedades o muertes cercanas de seres queridos, etc.), establecer turnos de descanso, darles el apoyo material necesario para realizar su trabajo, así como apoyo afectivo o reconocer la importante labor que realizan para la institución que representan y para la nación. Una vez acabada la intervención, se debe marcar una fecha para la puesta en común, la supervisión afectiva y la retroalimentación.

Tanto la capacidad de mantenerse estable, como de recuperarse tras acontecimientos traumáticos, se denominan resiliencia psicológica. Además de esta habilidad para resistir o adaptarse a situaciones difíciles, se ha descrito otra característica muy frecuente en personas que han sufrido un trauma y es la capacidad de experimentar crecimiento interior. Esta evolución positiva, denominada "crecimiento postraumático", se asocia con una percepción renovada de la vida, un cambio en las prioridades, aprovechamiento de nuevas oportunidades, fortalecimiento interior, mejoría de las relaciones personales y cambios espirituales (asociados éstos, o no, a sentimientos religiosos). Estas vivencias las han experimentado personas que se han enfrentado a diferentes tipos de traumas, como procesos de enfermedad grave o terminal, distintos tipos de duelo, o haber sobrevivido a guerras y catástrofes naturales.

El apoyo psicológico en situaciones de emergencia y crisis consiste, en resumen, en movilizar los mecanismos innatos y adquiridos de resiliencia de los afectados, con intervenciones en tres fases y basadas en la evidencia demostrada. Así, se agiliza la activación de sus estrategias de afrontamiento ante la situación $\mathrm{y}$, en fases posteriores, se favorece la adaptación, superación y el crecimiento postraumático.

Mónica García Silgo

Capitán Psicólogo.

Unidad de Apoyo Psicológico.

Inspección General de Sanidad.

Glorieta del Ejército 1. 28047 Madrid. España. 